American Journal of Economics and Business Administration 3 (2): 224-233, 2011

ISSN 1945-5488

(C) 2010 Science Publications

\title{
Turning Risks into Opportunities in Contract Management: A Case Study in the Health Care Industry
}

\author{
Elizabeth McVicker \\ Department of Management, School of Business, \\ Metropolitan State College of Denver, Campus Box 78, \\ P.O. Box 173362, Denver, CO 80217-3362, USA
}

\begin{abstract}
Problem statement: This case study presented students with a situation based in the healthcare industry, highlighting the importance of contract review, clear communications and interestbased negotiations in order to avoid the costly consequences that could be associated with contract related disputes. The case allowed students to understand how clearly written contracts play a deciding role in the success of business partnerships. Students practiced negotiation skills while discussing the performance clauses of the contract and considering effective amendments to that contract with the purpose of extending a business relationship. Approach: The author interviewed a project manager working for a preferred implementation vendor which had a contract with a large hospital provider in Colorado and California. The purpose of the interview and the case study focused on contract law, contract management, enterprise risk management and negotiation skills. The case study is based on class room use with practical, real-life contract management scenarios. Results: The team projects submitted for this case study in case management highlighted the receptivity of students in understanding the benefit of preserving business relationships, avoiding litigation and carefully wording the specifics of complex contracts. The students excelled in practicing interest-based bargaining skills and writing contract amendments that reflected the specifics of the complex contract problem presented. Conclusion/Recommendations: Case studies focused on real business situations resonate well with upper division students in business law classes; the complexities of the situations and of the contract language did not deter students from brainstorming solutions to the problems presented and in writing amendments to the contract such that the business relationship was preserved. The results of the students' work on this case study problem were presented to the consultant who was surprised at the level of contract management demonstrated by the students.
\end{abstract}

Key words: Contract management, interest-based bargaining, negotiation skills, stakeholder theory, Electronic Medical Records (EMR), compensatory damages, consequential damages, liquidated damages, ethical considerations, electrohospital consulting

\section{INTRODUCTION}

The context of this case is the healthcare industry, an industry that will likely be one of the significant employers of current undergraduate students in multiple managerial and administrative roles. The new healthcare reform act-the (Patient Protection and Affordable Care Act, 42 U.S.C. 300), et. seq.--requires that by 2012, all healthcare organizations that receive reimbursements from the federal government for Medicare services must prove "reasonable use" of electronic medical documents (42 U.S.C. 3501). Currently, only approximately $17 \%$ of all medical records are electronic. Although paper-based records have been used for centuries, their gradual replacement with computer-based records, or Electronic Medical Records (EMR), has been mostly used for administrative uses rather than clinical purposes. EMR systems, however, are crucial to a computerized health information system and will allow decision-support systems to operate in an integrated manner for all clinical workflows from diagnostic uses to wellness plans.

The implementation of the change from paper to electronic clinical documentation and the contracts between medical providers, software designers and IT consultants provide students with an authentic context where multiple parties are involved in a contractual relationship replete with the complexities of the scope of work, schedules, quality of deliverables and requirements of performance that can either bring demise to a business partnership or, given a clearly written and detailed contract, allow for a successful project and continued business partnership. 
Students will work in teams to address the possible issues of breach of contract and how to amend and preserve the contract. Negotiation skills will be emphasized and students will have a practical application of the ethical doctrine of stakeholder theory. Teaching notes based on suggested readings provide notes on legal principles of contract law, stakeholder theory, alternative dispute resolution procedures and negotiation skills. Because the situation is based on a federal act, the reach of federal statutory law and regulatory compliance are central to the case study.

The case study: Contract management electrohosptial consulting services, inc. and sterling hospital the implementation of electronic medical records: The students play the role of the Project Manager at Electrohospital Consulting Services, Inc. and the role of the Project Sponsor reporting to the Steering Committee at Sterling Hospital. The names of the consultant and the hospital, although fictitious, are based on real entities and a current relationship. The professional titles mirror those in the industry and are specific to the situation presented here.

Electrohospital Consulting Services is known as a "preferred implementation vendor" that helps hospitals and clinics in various ways, one of which is to implement new software, the key to the migration of paper records to electronic ones and a requirement of the new Patient Protection and Affordable Care Act, 42 U.S.C. 3501 (PPACA). The new law institutes a series of changes that will standardize billing while requiring health plans to adopt and implement rules for the secure, confidential electronic exchange of health information. The premise of the requirement of the law is that the use of electronic medical records reduces paperwork and administrative burdens, cuts costs, reduces medical errors and improves quality of care. The first regulations of this part of the PPACA are effective October 1, 2012, 42 U.S.C. 1561, 3501. Penalties will be assessed to those healthcare providers not in compliance with the electronic records requirements based on Medicare and Medicaid reimbursements from the federal government.

Electrohospital Consulting Services, Inc. contracts directly with hospitals and clinics in order to assist in the implementation of the use of the new software that will enable compliance with the PPACA regulations. Electrohospital does not have a contractual relationship with the software vendor-only the hospital does-which adds an additional twist to the contractual relationship.

In this case study, Electrohospital Consulting Services, Inc. has signed a fixed price contract with Sterling Hospital, a major hospital serving eastern
Colorado. The hospital administrators, the Project Sponsor and the Steering Committee, were in a cost control mode when they signed the contract and had not considered the unknown operational complexities that would arise with the implementation of their new software. Six months into the project, schedule slips have arisen, the quality of some of the deliverables is being questioned and the date of completion of the implementation is unsure. Sterling Hospital is owned by a larger hospital provider and another contract is pending for Electrohospital Consulting Services to provide similar services to a large hospital in California. The chance of getting that project is dependent on the successful completion of the Sterling contract.

The Project Sponsor for Sterling Hospital is the person responsible for oversight of the project for the hospital; this individual reports to the Steering Committee, a committee comprised of physicians, nurses and administrators which approves payments to the consultants and are responsible for the final "launch" of the new electronic records system. Since signing the contract with Electrohospital Consulting Services, Inc., the hospital has had changes in personnel and the original Project Sponsor has been replaced as well as one of the key physicians on the Steering Committee. The new physician on the Steering Committee has made multiple requests for substantial changes in the actual deliverables; the scope of these changes would not be characterized as "ordinary" in scope.

Meanwhile, the new Project Sponsor for the hospital has voiced concern about the quality of the work that Electrohospital has produced because of problems in certain testing phases and has expressed anger and frustration over schedule slips that have arisen. Indeed, the new Project Sponsor has requested permission from the Steering Committee to rescind the contract with Electrohospital, claiming breach of contract and has suggested another preferred implementation vendor, a competitor of Electrohospital, to take its place to finish the project.

Electrohospital has completed approximately $60 \%$ of the scope of work since the signing of the contract, seven months ago. The Project Manager for Electrohospital Consultant Services has realized the need for more direct communication with the hospital's Project Sponsor and Steering Committee and believes that, because of the changes that have been requested by the hospital, modifications to the contract must be made. Electrohospital's Project Manager has reviewed the contract with legal counsel and believes that, if the breach of contract claims that the hospital's Project 
Sponsor has threatened were to go forward, Electrohospital would have valid counter claims. However, the Project Manager wants to attempt in every way to preserve the relationship with Sterling Hospital, understanding the importance of successfully finishing the project so as to position Electrohospital in an ongoing business relationship with the parent hospital company of Sterling Hospital and to obtain additional projects.

The contract: Electrohospital's Project Manager and legal counsel first reviewed the basic elements of the original contract with the hospital:

- $\quad$ Contract price: Seven million dollars $(\$ 7,000,000)$ to be paid in monthly installments based on applications for payment and percentage of work completed

- Time of substantial completion: 16 months from date of commencement

- Scope of work: Defined generally that Electrohospital would "implement the new software" to enable physicians to enter medical documentation directly to the new software

- Reporting and communications: the clause states generally that the Project Sponsor from the hospital and the Project Manager from the consultant would have weekly meetings; the clause does not specify the medium or place of the meetings. The output of these meetings would be minutes which would serve as project status reports and would be transferred to the hospital's Steering Committee and to the consultant's VP

- Changes in requirements: The clause addresses "ordinary changes" and states that if the hospital requires ordinary changes not specified in the original contract, the hospital will notify the consultant as soon as possible and would pay additional accrued rates as stated in the contract. "Ordinary" is not defined. Specific time frames for requests for changes are not addressed. Payments for additional work are not stated

- $\quad$ Staffing plan: The clause specifies the personnel, nurses, physicians and IT specialists, that the hospital must provide to work in conjunction with the consultant to implement the software. These personnel requirements are crucial to the implementation of the software and the use of the software once the consultant has completed its work and departed from the hospital

- $\quad$ Claims disputes: The clause requires that disputes must first be addressed internally with specific dispute resolution procedures, based on negotiations between the key personnel of the hospital and the consultant. If negotiations fail, the contract does not articulate a procedure for resolution of disputes although the clause requires the use of "Alternative Dispute Resolution Procedures” before a party can initiate litigation

- Substantial performance: This clause states that neither party can cancel the agreement, in whole or in part, subsequent to more than fifty percent of the consideration having been tendered by the other party. In addition, the clause states that the hospital cannot rescind the contract once $50 \%$ of the scope of work per the contract requirements has been completed by Electrohospital Consultant Services, Inc. unless the quality of the deliverables is unacceptable

- Confidentiality: The clause states that all work performed by Electrohospital Consulting Services Inc., is confidential and any work product would transfer to Sterling Hospital only when the project was complete.

Breach of contract claims by sterling hospital: Sterling Hospital's Project Sponsor is claiming breach of contract based on breach of substantial performance and wants to rescind the contract. He has requested an immediate transfer of all the unfinished work that Electrohospital Consulting Services has completed; this includes the documents prepared for test plans and training plans. The hospital's Project Sponsor claims a material breach of performance under the contract clauses that address the following:

- Reporting and communications

- Changes in requirements

- Substantial performance

Counter claims from electrohospital consulting services, Inc.: The Project Manager (PM) at Electrohospital understands the importance of successfully finishing this project and is focused on finding alternatives to litigating the breach of contract claims. The PM wants to articulate clear amendments to the contract in a mutually beneficial manner but knows that, as a first step, all legal claims that the hospital is making must be answered. In their meeting, Electrohospital's legal counsel and the PM discuss the contract and possible counterclaims to the breach of contract claims asserted by Sterling:

- Reporting and communications: Electrohospital believes that Sterling would be in breach of contract under this clause because of the changes in 
its project management personnel. The new Project Sponsor did not comply with the required weekly meetings and in subsequent meetings, the minutes were not disseminated to the Steering Committee

- Changes in requirements: Electrohospital believes that Sterling would be in breach of contract under this clause because the hospital has continually changed the requirements of the Project outside the scope of "ordinary." These substantial changes caused delays in the deliverables. The original contract did not clearly outline a process for changes; the only requirement was that all changes be agreed to by both parties and signed off by an executive from Sterling. This did not occur because of the change in personnel at Sterling Hospital

- $\quad$ Staffing plan: Electrohospital believes that Sterling Hospital would be in breach of contract under this clause because the hospital did not provide the required and specified inside staff, neither IT nor nursing staff, that are needed for the successful handover of the implementation process

- Claims dispute: Electrohospital believes that Sterling Hospital would be in breach of contract under this clause because the hospital did not pursue any internal dispute resolution procedures. The new Project Sponsor at the hospital did not attempt any negotiations of any kind with the consultant nor pursue any alternative dispute resolution procedure as the contract requires. Instead, the hospital's Project Sponsor has threatened litigation based on breach of contract

- Substantial performance: Electrohospital believes that the scope of the changes requested by Sterling were not ordinary and changed the scope of work substantially. Electrohospital has also completed $60 \%$ of the original scope of work which, per the contract, should prevent Sterling from rescinding the contract. In addition, the burden of proof of claiming that the work was "low in quality" would be on Sterling and Electrohospital would be able to show how the changes requested affected the scope of work defined

- Confidentiality: Electrohospital discovered that Sterling Hospital had engaged in conversations with another "preferred implementation vendor" in taking over the contract from Electrohospital and that some of the scope of the project had been shared with the competitor.

Lawsuit and damages: The legal counsel for both Electrohospital Consulting Services, Inc. and Sterling Hospital meet with the lead managers of the project, the consultant's Project Manager and the hospital's Project
Sponsor, to discuss the threat of the potential lawsuit and to explain the consequences of such a lawsuit. The attorneys for both parties explain that if the breach of contract suit goes to court, the time and expense will be considerable. The District Court of General Jurisdiction in the county in which the hospital is located has a backlog of cases such that, even if the hospital were to file its complaint today, the case would most likely not come before a judge for six months. The discovery process alone will take months to prepare and will cost each side tens of thousands of dollars before either party has their "day in court." The damages which a judge could award to one party or the other could include:

- Compensatory damages

- Consequential damages

- Liquidated damages

- Attorney fees and costs

- Rescission of the contract

- Reformation of the contract

The Project Sponsor of the hospital, without showing any sign of backing off his threat of litigation, takes careful notes so as to be able to report back to the hospital's Steering Committee. The Project Manager of Electrohospital Consulting Services also takes notes in order to brief her VP but makes comments to the hospital's counsel and Project Sponsor about the possibilities of direct negotiations and the need to amend the contract. She requests another meeting in three days.

Negotiations: The Project Manager of Electrohospital Consulting Services, Inc. convened a meeting with her VP to discuss how to best approach the Project Sponsor and Steering Committee of the hospital in negotiations in order to amend the contract and continue the project. As a fortunate coincidence, the President of Electrohospital had sent the VP and the Project Manager to an executive training on strategic negotiation skills in Hawaii just the previous month. This training emphasized the benefits of interest-based bargaining, or integrative bargaining, a negotiation strategy articulated and explored by Fisher et al. (1992) in their classic text, Getting to Yes: Negotiating Agreement Without Giving In, which emphasizes how parties can find a "win-win" solution to their dispute by focusing on mutually beneficial agreements based on the interests of the parties.

The PM remembered how the trainer in the Hawaii negotiation trainings couched the benefits of interestbased negotiations in the context of the "aloha spirit" 
which serves as the foundation for the belief systems and way of living of Hawaiians. "Aloha" means being able to recognize and appreciate the uniqueness and differences of each person and what that person might be bringing to the negotiation table. One who act with the "aloha spirit" is patient and kind, not proud, not rude, not easily angered, not self-seeking and keeps no records of wrongs but rather trusts and perseveres while still being protective. Electrohospital's PM was determined to enter her negotiations with Sterling Hospital with the aloha spirit.

In the meeting with the attorneys for Electrohospital and Sterling Hospital, the hospital's Project Sponsor was entrenched in his position and was holding tight to pursuing an accommodative type of negotiation, insisting that the consultant give in on every point. The hospital's Project Sponsor was definitely practicing distributive bargaining, which is "basically a fight over who is going to get the most of a limited resource" (Lewicki et al., 2010). This kind of negotiation is used for one-time deals for zero-sum situations and focuses on "resistance points." This was not an option for Electrohosptial that has its eye on a continued business relationship. Instead, determined to save the contract and the relationship, Electrohospital's PM realized that the kind of negotiation process that she and her team will pursue will be interest-based bargaining; she was confident that she and her team could find a "win-win" outcome for both the hospital and the consultant, amending the contract in a clear manner so as to avoid any possibility of expensive litigation.

Electrohospital's VP asked the PM to articulate the BATNA-Best Alternative to A Negotiated Agreement, articulated as a starting point by Fisher et al. (1992) for successful negotiations. The PM realizes that the alternative actions that will be taken should her proposals fail to materialize in an amended contract, arbitration or litigation, are not acceptable. She, thus, calls her team together to brain-storm alternatives that can be included in contract amendments and which she can present to the hospital's Project Sponsor at their scheduled meeting in three days.

Contract amendments: Suggested alternatives, inventing options: The Project Manager of Electrohospital Consulting Services convenes a brainstorming session with her team to come up with as many options as possible to present to Sterling Hospital in order to try to amend the contract, turn potential liabilities into opportunities and to save the project. Among these options are the following:

- Communication: In addition to the weekly meetings between the project management team of
Electrohospital and the Project Sponsor of the hospital, the team suggests that daily status reports be uploaded to the Electrohospital's extranet such that key personnel of both the hospital and the consultant can stay abreast of the implementation of the software. The team also suggests that they invite a nurse and an IT specialist from the hospital to be on the Electrohospital team implementing the process

- Requirements Changes: The team suggests that the hospital and the consultant designate and appoint a committee to oversee changes. This "change control committee," consisting of software engineers from both the hospital and the consultant, will review change requests and if they appear to be valid and agreed to by both parties, to reduce the changes to a writing that becomes part of the contract's scope of work. The "change control commitee" will monitor all agreed-upon changes. The contract amendment that addresses the change process will specify additional costs to be added to the contract sum and the hospital will agree to compensate Electrohospital for new requirements according to how many features are added and when those were added. The fee scale will be agreed to by both parties

- Staffing Plan: The team suggests that, in order to emphasize the crucial aspect of the need for the hospital to designate adequate staffing for the implementation process, that Electrohospital offer to add additional IT specialists. The cost of adding this additional staff from Electrohospital would be negotiated; the team suggests that the hospital split the costs with Electrohospital but that this could be a point of concession for Electrohospital's negotiations. The number of additional software engineers would be a point of negotiation between the hospital and the consultant as well

- Performance: The team suggests that the hospital and Electrohospital designate a board to oversee the quality of the software once it is actually being used by physicians and nurses at the hospital. This board would work in tandem with Sterling's testing group such that any "bugs" in the system are "owned" by both parties. The addition of at least five Electrohospital engineers and IT specialists to the Sterling project will assist in speeding up the completion of the project and as noted in the discussions of the staffing plan, the costs of the additional staff would either be split between Sterling Hospital and Electrohospital or the consultant could be willing to absorb these costs 
- Claim Dispute: The team suggests that in case further disputes arise, the Steering Committee of the hospital and the VP of Electrohospital appoint an outside ombudsmen to assist in direct negotiations and that a time line be specified for such negotiations. The team further suggests that the contract be amended to add specific alternative dispute resolution procedures with definite, short time lines, such that any negotiations would proceed directly to mediation and that the mediation rules of the American Arbitration Association be articulated in the contract language

The Project Manager at Electrohospital Consulting Services is a good facilitator and is able to inspire the team to add other solutions to the problem at hand to present to Sterling Hospital. The team is directed to specify timelines and any additional fee schedule in every amendment proposed. The PM and the team decide that the options presented should be prioritized.

Anticipating successful negotiations with Sterling, the Electrohospital Consulting Services Project Manager asks her team to draw up a list of the alternatives to the project and to draft contractual language for possible amendments to the existing contract. The team will outline these in its assignment in a business memo format directed to Electrohospital's VP who will review before the meeting with the hospital Project Sponsor and Steering Committee.

\section{Discussion questions and teaching notes in preparation of team assignment: \\ Legal issues of contract formation and enforcement:}

- Is the contract between Electrohospital Consulting Services, Inc. and Sterling Hospital an enforceable contract? Identify the elements of the contract. Are the terms definite?

- Students will define the purpose of a contract, the elements of an enforceable contract and discuss the ambiguity of the contract language and the risks that such indefinite terms present. All business law text books cover these basics. See, for example, Beatty and Samuelson (2007). The suggested primary resource is the Restatement (Second) of Contracts $\S \S 1,17$, 21, 209 (American Law Institute, 1981)

- Identify the consideration in the contract. Does the issue of preexisting duty arise in this contract dispute? Discuss the issue of the additional work or unforeseen circumstances. How will Electrohospital use this in its negotiations with the hospital?
- Students need to recognize that consideration has been tendered by both parties and that, even as Sterling Hospital threatens legal claims, the contract is enforceable and that, indeed, Electrohospital has grounds to demand additional consideration because of the additional work and unforeseen circumstances. Again, all business law text books will include discussions on consideration, preexisting duty and additional work. See, for example, Beatty and Samuelson (2007). The suggested primary resource is the Restatement (Second) of Contracts $\S \S 71,79$

- Is this contract ruled by the Uniform Commercial Code or by common law? Why?

- Students will discuss the sources of contract law and identify that this contract will be ruled by common law because the predominant purpose of the contract is services, not goods. All business law text books include references to this information. See, for example, Beatty and Samuelson, 2007, pp. 223-225. The primary resource is the Uniform Commercial Code Article 2

- Analyze the issues of consent and mistake if they apply to this contract situation. Have both parties upheld their respective duties of good faith and fair dealing?

- This crucial tenant of contract law is important to emphasize for students and can serve as a point of departure for their negotiation strategies based on legal premise. The Restatement (Second) of Contracts §205 states that "every contract imposes upon each party a duty of good faith and fair dealing in its performance and its enforcement" and emphasizes that the parties must remain faithful to the "agreed common purpose and justified expectations of the other party"

- Is there a third party beneficiary to this contract? Analyze Electrohospital's duty to have anticipated problems with the software vendor?

- Students will discuss the role of the software vendor who has contracted directly with the hospital. This relationship should encourage discussion of the definitions of the third party beneficiary in Restatement (Second) of Contracts §302: A beneficiary of a promise is an intended beneficiary and may enforce a contract if the parties intended that party to benefit and if enforcing the promise will satisfy a duty of the promise to the beneficiary 
- Can Sterling Hospital assign this contract to another preferred implementation vendor?

- Because students routinely deal with contracts that have assignment clauses in them, this question will help them focus on the fact that any contractual assignment may be assigned unless assignment is precluded by the contract itself or would substantially change the obligor's rights or duties under the contract. Restatement (Second) of Contracts §317(2)

- Can Electrohospital Consulting Services, Inc. delegate any of its duties described in the scope of work in the contract?

- $\quad$ The Restatement (Second) of Contracts $\$ 318$ makes clear that an obligor may delegate his duties unless the obligee has a substantial interest in personal performance by the obligor. Because a majority of the study has been completed by Electrohospital, this fact will also be useful in the team's preparations for negotiations with the hospital

- Are there any conditions precedent in this contract or conditions subsequent? Who will bear the burden of proving that these conditions have been met, the hospital or the consultant?

- The Restatement of Contracts §§ 224 et seq explains the distinctions between these conditions based on the burden of proof of the plaintiff or the defendant. Students will understand again, the importance of avoiding legal action.

- The contract requires concurrent conditions because both parties have a duty to perform simultaneously. Describe the parts of the agreement that require concurrent conditions

- This discussion will be key to the negotiations of the case study because the students will focus on the importance of the hospital staff working side by side with the consultant. Restatement (Second) of Contracts $\$ 227$

- What is the substantial performance doctrine? Analyze the state of the contract between the hospital and the consultant to decide if Electrohospital has substantially performed?

- All business law texts, such as those Beatty and Samuelson (2007), emphasize that courts analyze key questions when deciding substantial performance such as how much benefit has been received and if the parties have acted in good faith

- Explain material breach of the contract. Can Sterling Hospital claim material breach of the contract by Electrohospital Consulting Services, Inc.? Why or why not? Contrast substantial performance with strict performance.

- Restatement (Second) of Contracts \$237 explains the difference between strict performance and substantial performance. In their negotiation strategies, students will use the fact that the consultant has substantially performed and should receive the value of its work if the hospital wants to terminate the contract

- Explain the effect of the statute of limitations if the hospital wants to pursue legal claims. How does the answer to number 3 above effect the answer to this question.

- A statute of limitations begins to run at the time of injury. Students will be reminded that statutes of limitations vary from state to state and from issue to issue within a state. The fact that this situation begins in Colorado but that the hospital provider has headquarters in California will add to the discussions. Also, students will reflect on the fact that this is a service contract ruled by common law and will come under different statutes of limitations from a contract that is ruled by the Uniform Commercial Code. See, for example, Beatty and Samuelson (2007)

- Would this contract have a force majeure clause? Why or why not?

- To protect themselves from unexpected events, many parties to contracts include a force majeure clause, allowing cancellation of the agreement in case of extraordinary and unexpected events. The students will discuss whether or not this kind of contract would include such a clause and will most likely decide that it would be a good idea to include in the contract amendments. Earthquakes, fires or other acts of God can happen anywhere and delay the work defined in a contract

- Define compensatory damages. Define consequential damages. Define liquidated damages. Define punitive damages. If Sterling Hospital insists on pursuing legal action for breach of contract against Electrohospital, will it be successful in receiving any of these damages? Which ones? In contrast, if Electrohospital were to prevail in court, which damages would it most likely collect?

- The discussions around damages will motivate students to pursue interest-based negotiations 
and attempt to bring the hospital and the consultant back to the table for contract amendments. The amount of money that could be at issue is daunting. Various sections of the Restatement (Second) of Contracts as well as all business law textbooks explain the differences. Restatement (Second) of Contracts §§344, 345, 347, 351, 355, 356, 359

- $\quad$ Explain Alternative Dispute Resolution procedures. Explain mediation and arbitration.

- The fact that the consultant desires to have an ongoing relationship with the health care provider that owns Sterling Hospital will inspire students to see the benefits of mediation. Students should include a clearly written dispute resolution clause in the contract that outlines timelines for negotiations, mediation and arbitration. Students will be encouraged to reference and use the information from the American Arbitration Association website: www.adr.org

\section{Negotiation strategies:}

- What are characteristics of a good negotiatior?

- In his book, The Negotiating Game, Chester A. Karrass states that research shows that among important bargainer characteristics are the following: preparation and planning skills, thinking under pressure, good judgment and keen intellect, verbal expressions, product knowledge, perception of power and integrity. Listening ability and a willingness to use team assistance are key

- What is a BATNA?

- In their book, Getting to Yes, Fisher et al. (1992) explain how defining the Best Alternative to a Negotiated Agreement plays an important role in protecting against hard bargainers

- What is accommodative bargaining? What is distributive or Position-Based Bargaining?

- In their book, Essentials of Negotiation, Lewicki et al. (2010) explain that accommodative bargaining is when one party gives in on every point and how this is not really negotiation. Lewicki explains that distributive bargaining is usually used for onetime deals for zero-sum situations. A discussion of accommodative bargaining will assist students in seeing the benefits of interest-based bargaining

- What is Integrative or Interest-Based Bargaining?
- $\quad$ Fisher and Ury's classic text on interest-based bargaining should provide students with the tools and confidence to write the assignment called for in this case study. At the heart of interest-based bargaining is the concept of focusing on interests, not positions and on inventing options for mutual gain

- Outline a negotiation strategy for Electrohospital Consulting Services, Inc. to use in its discussions with Sterling Hospital. As the Project Manager for Electrohospital, what steps will provide the best chance of achieving the goal of amending the contract, completing the project and preserving the relationship with Sterling Hospital and its parent company?

\section{Ethical considerations: Stakeholder theory}

- What is stakeholder theory?

- In Chapter 2, pages 28-55, of their textbook, Business Ethics: Ethical Decision Making and Cases, Ferrell et al. (2006) discuss the importance of stakeholder relationships, social responsibility and corporate governance. Customers, investors, shareholders, employees, suppliers, government agencies, communities and in this case, patients all have a "stake" in the outcome of this contract dispute. Students should identify the primary and secondary stakeholders and insist upon including discussions around stakeholder orientation for their planned negotiations. Implementing the EMRs can be seen as a parallel to implementing a stakeholder perspective, part of which includes the identification of resources, the determination of urgency and making sure that stakeholder feedback is part of the agreement

- Who are the stakeholders in this situation?

- How can Electrohosptial's PM use her knowledge and consideration of stakeholder theory in her negotiations with Sterling Hospital?

Class assignment: The class will be divided into teams of four or five. Each team is the collective lead Project Manager at Electrohospital Consulting Services, Inc. and is required to write a memo to the VP of Electrohospital explaining the situation with Sterling Hospital. The memo will explain the basic elements of an enforceable contract, the problems and risks that have arisen since first signing the contract with Sterling Hospital and the problems that have arisen due to the 
ambiguities of the language in certain key clauses of the contract. Drawing from class readings and discussion questions, the team will brief the VP on the threat of breach of contract claims and possible damages that could ensue. Choosing at least three of the alternatives that arose in the "brain storming session," the team will outline its negotiation position strategically planned to maximize the opportunities in the situation and minimize the risk of litigation. The memo will be written with a persuasive tone, anticipating that Electrohospital will prevail in bringing Sterling Hospital back to the bargaining table, amending the contract and continuing the implementation of the new software for electronic health records.

The purpose of the assignment is to assist students in identifying the legal issues in the Case Study and reviewing the legal principles of contract law summarized in the discussion questions. Students will finish the assignment with an understanding of the importance of reviewing an existing or new business contract. Key to the assignment is the work that the teams of students will perform in order to develop a negotiating position in which the team will argue performance of the contract and the amendment of the existing contract. The goal is to prevent a dispute from escalating to legal action.

Each team will write a memo, business memo format, discussing the basic legal principles of contract formation, breach of contract, contract remedies, the risks of litigation, as well as the opportunities that may be present to continue the business relationship and avoid litigation.

In summary, the memo will include the following:

- Discussion of the basics of the formation of a legal, enforceable contract

- Discussion of the bases for the threat of breach of contract presented in the case

- Discussion of the remedies that each party may consider

- Identification of actions that the consultant can take in order to avoid the legal risks presented in the case study;

- Discussion of how a manager in the position similar to that of the PM for Electrohospital can minimize the potential liabilities of breach of contract claims and instead, pursue negotiations for opportunities to amend the contract and continue the relationship

- Identification, discussion and explanation of alternative solutions for the problems identified in the case study. The memo will explain why you choose certain alternatives as the best way to continue the relationship and avoid litigation
The team memo should be approximately 2,000 words in length, with clear paragraph transitions, correct grammar, punctuation and spelling, using APA format and including a final reference section.

\section{CONCLUSION}

This situation is based on a real, current relationship between a preferred implementation vendor owned by a large health care insurance company and a large for-profit hospital conglomerate based in California. Both parties rallied to amend the contract in a beneficial manner that allowed the completion of the project. The time for substantial completion, however, expanded from sixteen months to twenty six months. The key to successful completion was the team staffing between the hospital and the consultant: the hospital provided dedicated nursing staff and both the hospital and the consultant added additional IT specialists. The consultant is currently working on another implementation project at another hospital owned by the medical provider.

No matter what the outcome of the attempts to repeal the new Patient Protection and Affordable Care Act, the electronic conversion of medical records will be ongoing. As noted in a study by Coiera et al. (2005) published in the Journal of American Medical Information Association: "[C] computerization, with the Electronic Medical Records (EMR) at the centre, is effectively the only way forward...For the first time, the responses have been national and coordinated. Governments in Australia, Canada, Denmark, Finland, France, New Zealand, the UK, the USA and other countries have announced-and are implementing-plans to build integrated computer-based national healthcare infrastructures based around the deployment of interoperable electronic medical record systems." Clear, unambiguous contract negotiations will facilitate this revolution in health care and new graduates of business schools throughout the world need to be equipped to pursue the business partnerships that are key to implementing EMR systems.

\section{REFERENCES}

American Law Institute, 1981. Restatement (Second) of Contracts. American Law Institute. http://www.lexinter.net/LOTWVers4/restatement_ \%28second\%29_of_contracts.htm

Beatty, J.F., S.S. Samuelson, 2007. Essentials of Business Law. 3rd Edn., Thomson/Southwestern, USA., ISBN-10: 0324537123, pp: 1100. 
Coiera, E.W., A.S. Gosling and J.I. Westbrook, 2005. Do online information retrieval systems help experienced clinicians answer clinical questions? J. Am. Med. Inform. Assoc., 12: 315-321. DOI: 10.1197/jamia.M1717

Ferrell, O.C., J. Fraedrich and L. Ferrell, 2006. Business Ethics: Ethical Decision Making and Cases. 7th Edn., South-Western College Pub., USA., ISBN-10: 0618749349, pp: 528.
Fisher, R., W.L. Ury and B. Patton, 1992. Getting to Yes: Negotiating Agreement Without Giving In. 2nd Edn., Houghton Mifflin, Boston, ISBN-10: 0395631246, pp: 200.

Lewicki, R.J., B. Barry and D.M. Saudners, 2010. Essentials of Negotiation. 5th Edn., McGrawHill/Irwin, New York, ISBN-10: 0073530360, pp: 290. 